\title{
Migration Model and Dynamics Parameters of Large-Sized Yellowtails in the Pacific along the Japanese Coast Inferred from Tag Recaptures after the Year of Release
}

\author{
Syoiti TANAKA* \\ (Accepted December 27, 1983)
}

\begin{abstract}
A system model on fishing, migration and survival of tagged yellowtails after the year of release was developed to get quantitative information on migration pattern and natural mortality. Long term recapture data in second year and after from 1926-1938 releases were analysed, and various parameters were estimated. The results of the analysis generally justified the model. During the fishing season, very high proportions of fish disappeared from Kumano-nada and Tosa Bay similar to the case of the same year recaptures. Discontinuity in the distribution of fish at these points was reaffirmed. Majority of the fish released in areas north from Kumano-nada reappeared first to Kumano-nada next year, while the fish released in Kyushu area returned to the same area. The natural mortality rate were estimated to be $57-70 \%$ with weighted mean of $61 \%$. These values were possibly overestimated by factors such as tag shedding and tagging mortality. No southward shift of the areas of recapture was observed according to the number of years after release for the releases in north from Kumano-nada, and rather homogeneous age composition was suggested among the areas. Some discussions were presented on the estimation errors of the rate of disappearance and the natural mortality rate.
\end{abstract}

Although tagging experiments are powerful method for describing movement and migration of fish, it is usually not easy to analyse quantitatively if fish are released and recaptured from many places for a considerably long period. An attempt was made in the previous paper ${ }^{1)}$ to overcome this difficulty by constructing a system model of migration and dynamics of the tagged fish in the year of release. The method was generally successful and estimates of parameters such as the fishing rate and rate of disappearance from fishing ground were obtained for the largesized yellowtails in the Pacific along the Japanese coast. In the tagging of the yellowtails, a number of the tagged fish continued to be recaptured after the year of release. From these data it is possible, by expanding the model to long term recaptures, to estimate the yearly survival rate and proportion of fish returning to each fishing ground next year. Further, it is expected that some information on the reliability of the estimates would be obtained by examining the consistency between the results from the tag recaptures in and after the year of release. For these purposes, a model is developed and the data of tag recaptures after the year of release obtained from the releases conducted in
1926 to 1938 period are analysed in this paper.

\section{Method and Materials}

\section{System Model for Recaptures after the Year of Release}

In order to develop a system model for the tag recaptures after the year of release, following assumptions are made referring to the observed pattern of the tag recaptures. ${ }^{27}$ The definition of the areas used below are given in Table 1 .

1) Releases from areas 1 and 2 will reappear next year in area 1 or area 2 first.

2) Releases from areas 3 and 4 will reappear next year in area 2, area 3 or area 5 first.

3) Releases from area 5 will reappear next year in area 3 or area 5 first.

4) Within season migration route of the tagged fish after first reappearance in an area next year is the same as that in the year of release.

5) Those fish which disappeared from fishing grounds in a year and do not reappear to any fishing ground next year are assumed to have died by natural causes.

The system model is shown in Fig. 1 taking the releases in areas 1 and 2 for example. The re-

* Ocean Research Institute, University of Tokyo, Nakano, Tokyo 164, Japan（田中昌一：菓京大学海洋研 究所). 


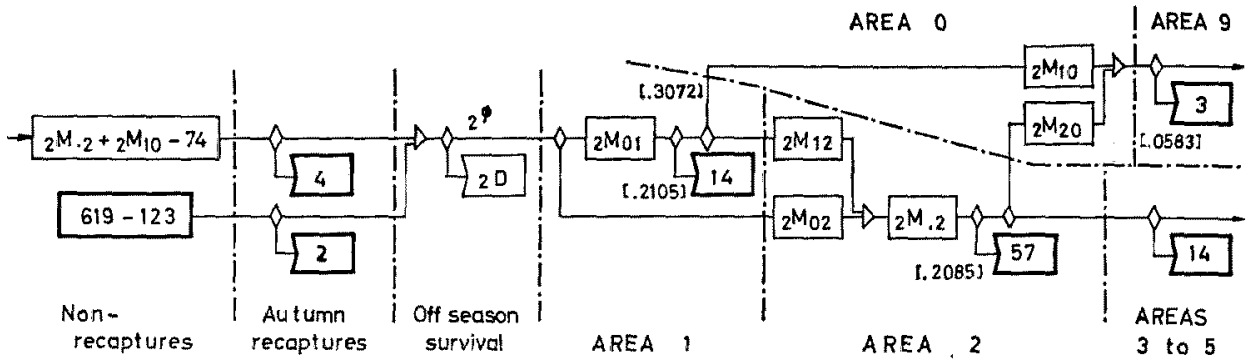

Fig. 1. Structure model of migration of yellowtails released in areas 1 and 2. All recaptures after the year of release combined.

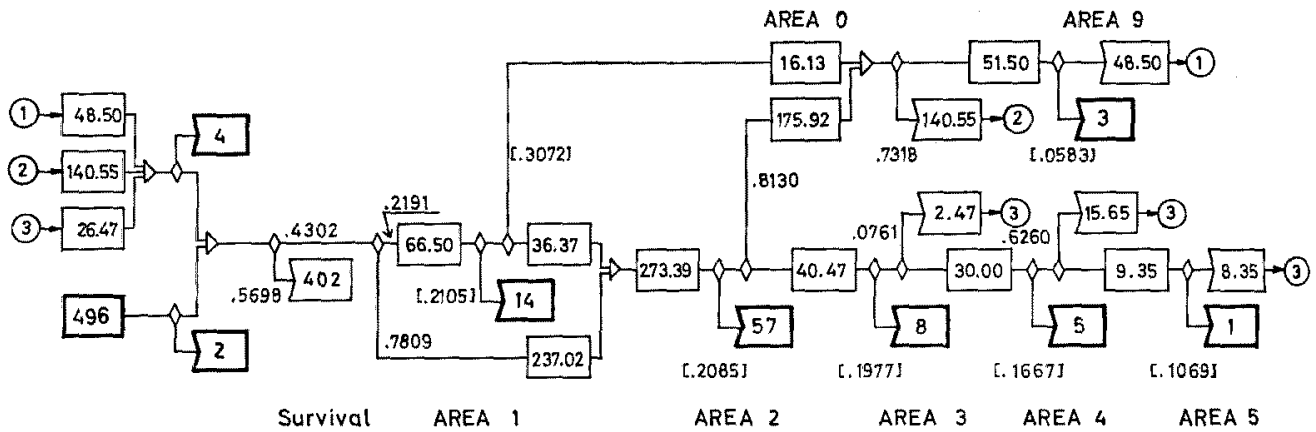

Fig. 2. Dynamics of yellowtails released in areas 1 and 2. All recaptures after the year of release combined.

captures extended over second to fifth years but all recaptures other than the same year recaptures are combined in this figure. Marks and notations used are identical with those in the previous papers. ${ }^{1,3}$ )

\section{Method of Calculation}

Basically the method of calculation is the same as that used in the previous paper. ${ }^{1)}$ Releases in areas 1 and 2 , areas 3 and 4 and area 5 are treated separately. The fishing rate of the tagged fish in second year and after in a fishing ground is assumed to be equal to the value in the year of release in the same fishing ground. The rate of disappearance from area 1 of the fish released in areas 1 and 2 in and after second year is assumed to be equal to the value for the year of release. Also for the releases from areas 3 and 4 and area 5 , the corresponding rates of disappearance referred from the previous paper are applied if necessary. For areas 1 and 2, fairly many fish were recaptured even after second year, and the recaptures in and after second year are treated separately as well as the combined data.

\section{Data}

Data from the same source ${ }^{4}$ as the previous paper are used. They are given in Table 1. Details for the same year recaptures are presented in the previous paper. Division of fishing grounds and area codes are same as before and shown in Table 1.

\section{Results}

Results of calculations are illustrated in Figs. 2-6. All fishing rates applied are those estimates from the same year recaptures and no new estimate is obtained. Some of the rate of disappearance are newly estimated. The natural mortality rate and proportions of fish first reappearing to each fishing ground are calculated. Values of these rates and proportions are tabulated in Table 2. The results may be summarized as follows.

The rate of disappearance from area 2 was very high being more than $80 \%$ both for the recaptures in and after the year of release. Discontinuity between area 2 and area 3 suggested in the previous paper ${ }^{1)}$ was endorsed. Some of fish which disappeared from areas 1 and 2 reappeared in 
Table 1. The number of releases and recaptures of the large-sized yellowtails along the Pacific coast of Japan. Detailed data for the long term recaptures from releases in 1926-1938

\begin{tabular}{|c|c|c|c|c|c|c|c|c|c|c|c|c|c|c|c|c|c|c|c|c|c|}
\hline \multicolumn{3}{|c|}{ Releases } & \multicolumn{19}{|c|}{ Recaptures } \\
\hline \multirow[b]{2}{*}{ Area*1 } & \multirow[b]{2}{*}{ Month } & \multirow{2}{*}{ Number } & \multirow{2}{*}{ Total } & \multicolumn{2}{|c|}{ 1st yr. } & \multicolumn{7}{|c|}{ Second year } & \multicolumn{5}{|c|}{ Third year } & \multicolumn{3}{|c|}{ 4th yr. } & \multirow{2}{*}{$\begin{array}{r}5 \text { th } \\
2\end{array}$} \\
\hline & & & & $1-9$ & $0^{* 2}$ & 1 & 2 & 3 & 4 & 5 & 9 & $0^{* 2}$ & 1 & 2 & 3 & 4 & 5 & 2 & 3 & 5 & \\
\hline 1 & Feb., Mar. & 114 & 47 & 43 & & 2 & 1 & & & & & & & & & & 1 & & & & \\
\hline 2 & Mar.-May & 402 & 148 & 74 & $2^{* 3}$ & 7 & 34 & 3 & 3 & & 1 & $4 * 3$ & 2 & 8 & 3 & 1 & & 4 & 1 & & 1 \\
\hline 3 & Mar., Apr. & 86 & 42 & 34 & & & 2 & 1 & & 1 & & $2^{* 4}$ & & 1 & & & & & & 1 & \\
\hline 4 & Mar.-May & 60 & 15 & 14 & & & 1 & & & & & & & & & & & & & & \\
\hline 5 & Mar., Apr. & 159 & 24 & 17 & & & & 1 & & 5 & & & & & & & 1 & & & & \\
\hline 9 & June & 103 & 22 & 6 & & 1 & 5 & 1 & 1 & & 2 & & 2 & 3 & & & & 1 & & & \\
\hline
\end{tabular}

*1 1: Sagami Bay; 2: Kumano nada; 3: East of Muroto; 4: Tosa Bay; 5: Kyushu; 9: Sagami Bay and north. summer recaptures

*2 0: Autumn recaptures

*8 Recaptured in area 2

*4 Recaptured in area 4

Table 2. Comparisons of estimated rates and proportions from various sources of data

\begin{tabular}{|c|c|c|c|c|c|c|c|c|c|c|c|c|}
\hline \multirow{2}{*}{$\begin{array}{l}\text { Area } \\
\text { of } \\
\text { release }\end{array}$} & \multirow{2}{*}{$\begin{array}{l}\text { Year } \\
\text { of } \\
\text { recapture }\end{array}$} & \multicolumn{5}{|c|}{ Rate of disappearance from area } & \multicolumn{5}{|c|}{ Proportion of fish which appeared first in area } & \multirow{2}{*}{$\begin{array}{c}\text { Survival } \\
\text { rate over } \\
\text { winter }\end{array}$} \\
\hline & & 1 & 2 & 3 & 4 & 0 & 1 & 2 & 3 & 4 & 5 & \\
\hline $\begin{array}{l}\text { All areas } \\
\text { (3) and (4) }\end{array}$ & $\begin{array}{c}\text { Same year } \\
\text { " }\end{array}$ & \multicolumn{5}{|c|}{$.7249 * 1$} & - & - & - & - & - & - \\
\hline (1) and (2) & 2nd yr. + & [. 3072] & .8130 & $\begin{array}{r}.0761 \\
.65\end{array}$ & .6260 & .7318 & .2191 & .7809 & 0 & 0 & 0 & .4302 \\
\hline$"$ & 2nd yr. & {$[.3072]$} & .8667 & . & . & .6402 & .2226 & .7774 & 0 & 0 & 0 & .4319 \\
\hline " & 3 rd yr. + & {$[.3072]$} & .6864 & . & $\ldots$ & 1 & .2108 & .7892 & 0 & 0 & 0 & .4262 \\
\hline (3) and (4) & 2nd yr. + & - & {$[.8066]^{* 3}$} & \multicolumn{2}{|c|}{$[.7111]^{* 4}$} & - & 0 & .4940 & .0546 & 0 & .4515 & .3039 \\
\hline (5) & 2nd yr. + & - & - & \multirow{2}{*}{\multicolumn{2}{|c|}{$[.7111]$}} & - & 0 & 0 & .0843 & 0 & .9157 & .3077 \\
\hline Weighted mean & & & & & & & & & & & & .3913 \\
\hline
\end{tabular}

Not calculated - Not applicable

(1 From Figs. 3 and 5 of previous paper, 1$)(146-44-28.06) /(146-44)$

*2 From Fig. 2, (40.47-13-9.35)/(40.47-13)

*3 Weighted mean of 8011 and $.8130,(203.76+175.92) /(254.35+216.39)$

*4 Weighted mean of .7249 and $.6596,(73.94+18.12)(102+27.47)$ 


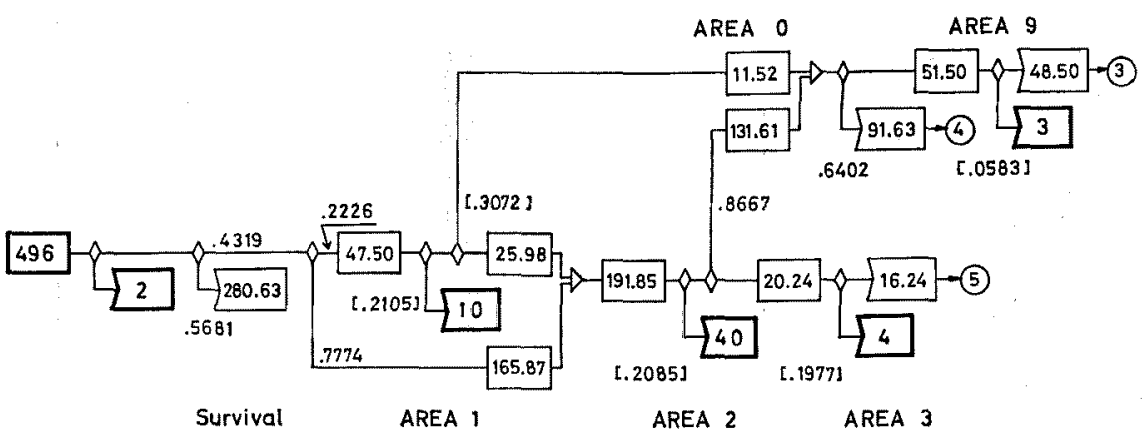

Fig. 3. Dynamics of yellowtails released in areas 1 and 2. Recaptures in second year only. Encircled figures are connected with the same figures in Fig. 4.

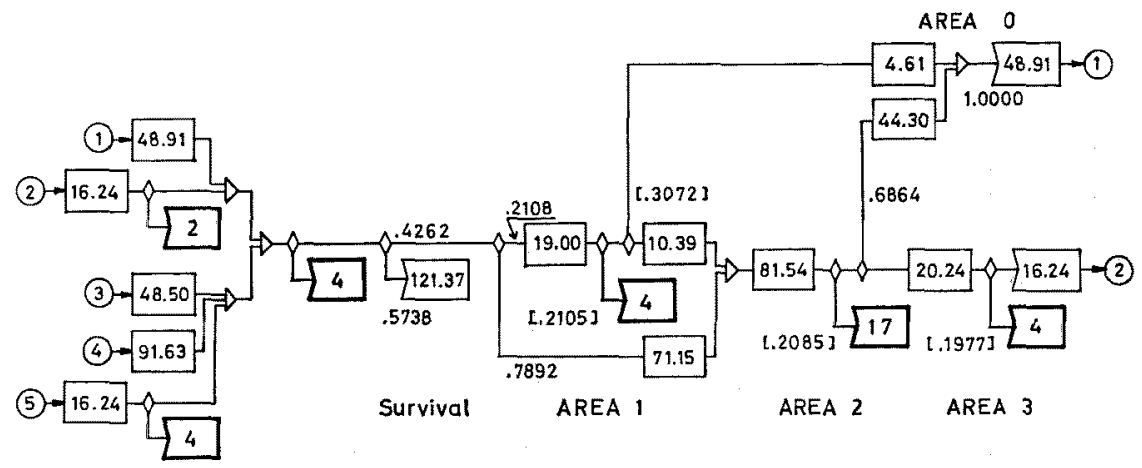

Fig. 4. Dynamics of yellowtails released in areas 1 and 2. All recaptures in third year and after combined. Encircled figures 3,4 and 5 are connected with the same figures in Fig. 3.

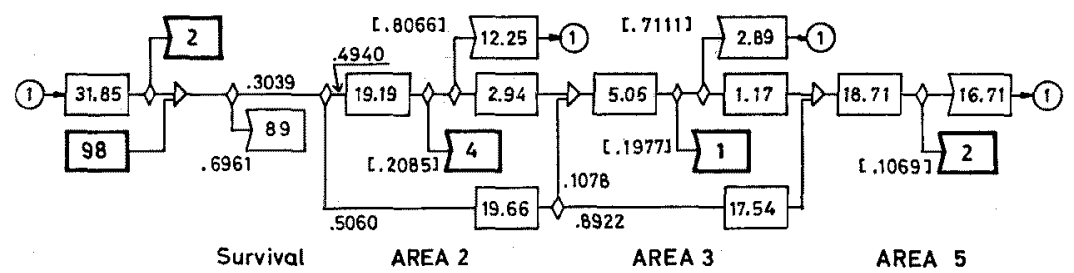

Fig. 5. Dynamics of yellowtails released in areas 3 and 4. All recaptures after the year of release combined.

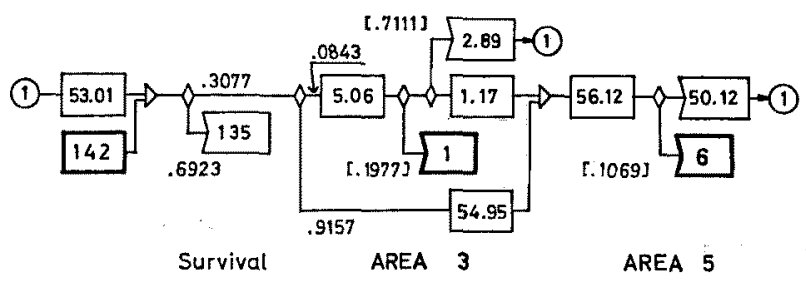

Fig. 6. Dynamics of yellowtails released in area 5. All recaptures after the year of release combined. 
summer season in area 9 but the majority did not reappear any fishing grounds in the same year. The rate of disappearance in area 3 was small and it was reaffirmed that most of the fish in area 3 moved into area 4. The majority of fish in area 4 disappeared and only a small portion moved to area 5. An overwhelming majority of releases in areas 1 and 2 returned to area 2 first next year, and only less than $20 \%$ occurred in area 1 . Although detailed examination was not possible for the releases in areas 3 and 4 and area 5 due to a small number of recaptures in second year and after, it was evident that the pattern of reappearance was considerably different from that for areas 1 and 2 . The fish released in areas 3 and 4 never reappeared in area 1 and contrarily a good part reappeared directly in area 5. No fish released in area 5 was recaptured in area 1 and area 2 , and the majority reappeared in area 5 directly.

Estimates of the survival rate ranged from $30 \%$ to $43 \%$. The weighted mean was $39 \%$. No tag shedding and tagging mortality were taken into consideration here, and hence these values were possibly underestimated.

Estimates from the recaptures in first year, in second year and in and after third year coincided well each other for the releases in areas 1 and 2. This indicated that the patterns of recaptures were very similar among these three groups and suggested a high reliability of the estimates.

\section{Discussions}

An attempt was made to estimate parameters of population dynamics of yellowtail. A new system model was developed by adding processes of the tagged yellowtails of survival to and reappearance into each fishing ground in next year, to the migration model within the fishing season set up in the previous paper. ${ }^{1}$ The parameters were estimated using the data of recaptures after the year of release. The results generally confirm those obtained from the same year recaptures. No unreasonable point which may negate the model is found and the model is considered to be reasonable basically.

The rate of disappearance was high in area 2 and area 4 , and this fact agrees well with the findings from the same year recaptures. The tagged fish returned mostly to area 2 or area 5 next year. A certain type of discontinuity due to either the population structure or the life history is suggested between area 2 and area 3, and also between area 4 and area 5 .
Table 3. Areas of recapture from tag releases in areas 1, 2 and 9 (Sagami Bay and north and Kumanonada) shown by the number of years after release

\begin{tabular}{|c|c|c|c|c|c|c|c|c|}
\hline \multirow{2}{*}{$\begin{array}{l}\text { No. } \\
\text { years }\end{array}$} & Area & (9) & (1) & (2) & (3) & (4) & (5) & \multirow[b]{2}{*}{$X$} \\
\hline & $X$ & -2 & -1 & 0 & 1 & 2 & 3 & \\
\hline 1 & & 3 & 10 & 40 & 4 & 4 & & -0.0656 \\
\hline 2 & & & & 11 & 3 & 1 & 1 & 0.2 \\
\hline 3 & & & & 5 & 1 & & & 0.1667 \\
\hline 4 & & & & 1 & & & & 0 \\
\hline
\end{tabular}

Since the spawning ground of yellowtail is located in the water adjacent to Kyushu, the distribution of fish may shift southward as they get older. Areas of recapture are shown in Table 3 separately by the number of years after release for the releases from areas 1,2 and 9. No clear southward shift is observed in the table. A variable $X$ which increases from north to south and takes 0 at area 2 is defined as shown in Table 3. Mean values $\bar{X}$ are very close to 0 for each line and no increasing trend according to the number of years is seen. Therefore, the discontinuity mentioned above is not likely due to the difference in the age composition of fish between areas.

As some estimates from the same year recaptures were used in the analyses of the recapture data after the year of release, the results from these two sources of data are not entirely independent. Errors in the estimation of fishing rate has been discussed in detail in the previous paper. These discussions are applied also to the results given in this paper. For releases in areas 1 and 2 , the rate of disappearance obtained from the data of the same year recaptures was used for area 1 (Figs. 2, 3 and 4). But this value has no effect on the estimates of the rate of disappearance in area 2 and southward. The rate of disappearance in area 0 and the survival rate could be affected by the error of this value. However, the number of fish which returned to area 1 first was small compared with that to area 2 and the effect of error is expected to be small. In Fig. 2, for example, if the value of 0.3072 is substituted by a extreme value, 1 or 0 , the rate of disappearance in area 0 is only modified from 0.7318 to 0.7876 or 0.7073 , and the survival rate from 0.4302 to 0.4581 or 0.4169 .

Detailed discussion is given below on the effect of errors in the fishing rates and the rates of disappearance on the estimate of the survival rate ${ }_{2} \phi$. Denoting the estimates by ${ }_{2} \hat{M}_{01},{ }_{2} \hat{M}_{02}$ and so on, the survival rate is

$$
{ }_{2} \phi=\left({ }_{2} \hat{M}_{01}+{ }_{2} \hat{M}_{02}\right) /\left({ }_{2} \hat{M}_{.2}+{ }_{2} \hat{M}_{10}+416\right)
$$


Substituting the relation

$$
{ }_{2} \hat{M}_{01}+{ }_{2} \hat{M}_{02}={ }_{2} \hat{M}_{.2}+{ }_{2} \hat{M}_{10}+14
$$

into the above formula and putting

$$
{ }_{2} \hat{M}_{.2}={ }_{2} M_{.2}+\Delta M_{.2} \text { and }{ }_{2} \hat{M}_{10}={ }_{2} M_{10}+\Delta M_{10}
$$

and further putting

$$
\Delta=\left(\Delta M_{.2}+\Delta M_{10}\right) /\left({ }_{2} M_{.2}+{ }_{2} M_{10}+14\right)
$$

then

$$
{ }_{2} \hat{\phi}=(1+\Delta) /\left(1 /{ }_{2} \phi+A\right)
$$

is obtained. From this formula

$$
{ }_{2} \phi={ }_{2} \phi /\left(1+\Delta\left(1-{ }_{2} \hat{\phi}\right)\right)
$$

As discussed in the previous paper, the fishing rate $p$ is possibly as small as a half of the true value, and hence ${ }_{2} \hat{M}_{.2}$ may be overestimated. That is, $\Delta M_{.2}>0$. While, ${ }_{2} \hat{M}_{10}=\left({ }_{2} \hat{M}_{01}-14\right) \times\left(1-\phi_{12}\right)$. In the right side, ${ }_{2} \hat{M}_{01}$ is possibly overestimated, and also $\phi_{12}$ is possibly overestimated since $\hat{M}_{12}$ could be overestimated. These two biases are cancelling each other in the estimate of ${ }_{2} \hat{M}_{10}$. Further, ${ }_{2} \hat{M}_{10}$ is much smaller than ${ }_{2} \hat{M}_{.2}$ in this example, and effects on $\Delta$ of ${ }_{2} M_{10}$ and $\Delta M_{10}$ can not be very large. The value of $\Delta M_{.2} /{ }_{2} M_{.2}$ could be as large as 1 . Putting ${ }_{2} \phi=0.4302$ and giving various values of $\Delta$ ranging from 0 to $1.0 \mathrm{in}$ formula (2), ${ }_{2} \phi$ is calculated and shown in Table 4. This table suggests that the survival rate could be overestimated by about $50 \%$ at most.

Both in the previous paper and this paper, error factors such as tag shedding, tagging mortality and oversighting of recaptured tags were neglected. For large-sized yellowtails, effects of these factors are expected to be small for a short term, but may be significant for a long term. The tagged fish lost by these causes were included in fish dead by natural mortality, and hence the survival rate tended to be underestimated. There is no available information on effects of these factors.

Dor $^{5)}$ estimated the survival rate of yellowtails around 1965 to be 0.33 . If the fishing rate is assumed to be not less than 0.275 , $^{\circ}$, the survival rate between fishing seasons would be not smaller than $0.33 /(1-0.275)=0.46$. This value is a little larger than the average of 0.39 or the largest value of 0.43 obtained in this paper, but the difference is not large.

The natural mortality coeffecient $M\left(=-\ln _{2} \phi\right)$ is fairly high being 0.78 for Dor's estimate and 0.94 for the average value of ${ }_{2} \hat{\phi}$ or 0.39 . If the smallest possible value in Table 4, or 0.274 is applied, a considerably high value of $M=1.295$ is obtained.
Table 4. Possible value of true survival rate ${ }_{2} \phi$, with estimated value of ${ }_{2} \hat{\phi}=0.4302$

\begin{tabular}{lll}
\hline \multicolumn{1}{c}{$\Delta$} & ${ }_{2} \phi$ & ${ }_{2} \phi /{ }_{2} \phi$ \\
\hline 0 & 0.4302 & 1 \\
0.1 & .4070 & 1.0570 \\
0.2 & .3862 & 1.1140 \\
0.3 & .3674 & 1.1709 \\
0.5 & .3348 & 1.2849 \\
0.7 & .3075 & 1.3989 \\
1.0 & .2740 & 1.5698 \\
\hline
\end{tabular}

At a glance it seems to be unreasonable that predatious large sized fish like yellowtail has such a high value of natural mortality. However, the natural mortality coefficient of yellowfin tuna, for instance, is also estimated to be close to $1.0 .^{7-10)}$ A value close to 1.0 for yellowtail could not be said unlikely. If $M=1.295$ given above is said to be too high, the error term $\Delta$ should be considerably smaller than 1.0. Underestimation of the fishing rate $p$ may not be serious.

\section{Summary}

1. A system model on fishing, migration and survival of the tagged yellowtails after the year of release was developed. The data of tag recaptures after the year of releases of the large-sized fish tagged in 1926 to 1938 period were applied to the model and the rate of disappearance from fishing ground, proportion of fish reappearing next year first to each fishing ground, and natural mortality rate were estimated. Some of these values were compared with the estimates from the same year recaptures.

2. The rate of disapearance during the fishing season was high in Kumano-nada and Tosa Bay likewise the results from the same year recaptures. Discontinuity in the distribution of fish at these points was reaffirmed. Majority of the fish released in Sagami Bay and Kumano-nada reappeared first to Kumano-nada next year, while the fish released in Kyushu area returned to the same area. Estimates of the natural mortality rate. between fishing seasons ranged from $57 \%$ to $70 \%$ $(M=0.84-1.20)$ and the weighted mean was $61 \%$ $(M=0.94)$. If such factors as tag shedding and tag martality were affecting, these values would be overestimation. For the fish released in Sagami Bay and Kumano-nada, no southward shift of areas of recapture was observed according to the number of years after release. Estimates from the recaptures in second year and in and after third 
year showed similar values.

3. The fishing rates for the tagged fish after the year of release and some of the rates of disappearance were assumed to be the same as that in the year of release. Even if this was not the case, effect on estimation error of the rate of disappearance would be small. It is possible that the bias of overestimation of the survival rate is as large as $50 \%$ but actually such a large bias seems to be unlikely.

\section{References}

1) S. TANAKA: Bull. Japan. Soc. Sci. Fish., 45, 297-303 (1979).

2) S. Tanaka: Bull. Japan. Soc. Sci. Fish., 39, 17-23 (1973).

3) S. TANaKa: Physiol. Ecol. Jap., 17, 513-518 (1976).

4) T. Matsushita and H. Ito: in "Saba to Buri no Hyoshiki Saiho Kiroku [Records of Tag Recoveries of Mackerel and Yellowtail]", Fisheries Science Series, Fisheries Agency, Vol. S, 1952, pp. $17-47$.

5) T. Dor: in "Mojako Saiho no Buri Shigen ni Oyobosu Eikyo ni Kansuru Kenkyu [Studies on the Effect of Fishing of Juvenile Yellowtails on the Adult Stock]", Kenkyu Seika, Norin Suisan Gijitsu Kaigi, Vol. 30, 1967, pp. 100-129.

6) Anon.: in "Mojako Saiho no Buri Shigen ni Oyobosu Eikyo ni Kansuru Kenkyu Hokokusho [Report on the Effect of Fishing of Juvenile Yellowtails on the Adult Stock]", Tokai Reg. Fish., Res. Lab. and Others, 1966, pp. 74-82.

7) R. C. HeNnemuth: Inter-Amer. Trop. Tuna Comm., Bull., 6, 1-51 (1961).

8) T. IsHII: Bull. Japan. Soc. Sci. Fish., 33, 738745 (1967).

9) T. IsHII: Bull. Japan. Soc. Sci. Fish., 35, 537-545 (1969).

10) Z. Suzukr: Stock assessment of yellowfin tuna in the Indian Ocean exploited by tuna longline fishery. Workshop on the Assessment of Selected Tunas and Billfish Stocks in the Pacific and Indian Oceans, Shimizu, 13-22 June 1979, SAWS/ BP/17 (1979). 